\title{
Pengaruh Gaya Kepemimpinan Demokratik Terhadap Kinerja Karyawan Dengan Menggunakan Motivasi Sebagai Variabel Moderator
}

\author{
Genefaith Grace Augi ${ }^{1)}$ \\ Fakultas Ekonomi dan Bisnis \\ Universitas Palangka Raya, Indonesia \\ Roby Sambung ${ }^{2)}$ \\ Fakultas Ekonomi dan Bisnis \\ Universitas Palangka Raya, Indonesia \\ Olivia Wiinda Ony Panjaitan 3 ) \\ Fakultas Ekonomi dan Bisnis \\ Universitas Palangka Raya, Indonesia \\ e_mail: genefaithaugi@gmail.com
}

\begin{abstract}
Abstrak
Tujuan - Penelitian ini bertujuan untuk memberikan penjelasan secara empiris tentang Pengaruh Gaya Kepemimpinan Terhadap Kinerja Karyawan Dengan Menggunakan Motivasi Sebagai Variabel.

Desain/Methodologi/Pendekatan - Metode penelitian yang digunakan dalam penelitian ini adalah pendekatan penelitian asosiatif-kuantitatif. Populasi dan sampel pada penelitian ini adalah seluruh karyawan PT.Telkom Indonesia Palangka Raya yang berjumlah 48 orang dengan teknik sensus. Data yang terkumpul dianalisis dengan menggunakan pendekatan Structural Equation Modeling (SEM) dan efek Moderasi dengan menganalisis menggunakan Partial Least Square (PLS). Software yang digunakan adalah SmartPLS 3.2.7.

Temuan penelitian - Hasil penelitian menunjukkan bahwa Gaya Kepemimpinan berpengaruh positif dan signifikan terhadap kinerja karyawan, dan Motivasi sebagai variabel moderator mampu memoderasi secara positif dan signifikan hubungan antara Gaya Kepemimpinan dengan Kinerja Karyawan di PT.Telkom Indonesia Palangka Raya.
\end{abstract}

Kata Kunci: Gaya Kepemimpinan Demokratik, Kinerja Karyawan, Motivasi Kerja Tipe artikel: Artikel penelitian

\section{The Effect of Democratic Leadership Styles on Employee Performance Using Motivation as A Moderator Variable}

\begin{abstract}
Purpose, -This study provides an empirical explanation of the effect of democratic leadership style to employee performance with motivation as a moderator variable.

Design /Methodology / Approach-The research method used in this research is associative-quantitative research approach. The population and sample in this study is the entire employee of PT.Telkom Indonesia Palangka Raya numbering 48 peoples with census technique. The collected data was analyzed using Structural Equation Modeling (SEM) approach with moderation effect and analyzed with Partial Least Square (PLS) approach. The software used was Smart PLS 3.2.7.

Research Findings - The result of the research indicates that democratic leadership has a significant and positive effect on employee performance, and motivation as a moderator variable has a significant and positive effect on relationship between democratic leadership style to employee performance on PT.Telkom Indonesia Palangka Raya.
\end{abstract}

Keywords: Democratic leadership style, Employee Performance, Work Paper Type: Research paper

Jurnal Manajemen Sains dan Organisasi

Vol 1, No 1, 2020 pp. $01-15$ FEB UPR Publishing $2685-4724$
Genefaith Grace Augi, Roby Sambung and Olivia Winda Ony Panjaitan. Published in the Jurnal Manajemen sains dan Organsasi. Published by FEB UPR Publishing Limited. This article is published under the Creative Commons Attribution (CC BY 4.0) licence. Anyone may reproduce, distribute, translate and create derivative works of this article (for both commercial and non-commercial purposes), subject to full attribution to the original publication and authors. 


\section{Pendahuluan}

Perubahan zaman dan perkembangan dunia bisnis yang semakin pesat menjadi sebuah fakta yang tak dapat terhindarkan. Oleh karena itu figur seseorang yang berpengaruh untuk memimpin dan mengatur menjadi sosok yang diperlukan dalam sebuah organisasi. Kinerja yang baik berhubungan dengan bagaimana seorang pemimpin dapat memberikan motivasi kepada karyawannya untuk meningkatkan kinerja. Data lapangan menyatakan bahwa, rata-rata hasil dari nilai kinerja individu (NKI) penilaian kinerja karyawan yang dilakukan, hasilnya berkisar antara 70\% - 75\% prestasi kinerja karyawan, seharusnya mencapai hasil kinerja diatas 80\%. Gaya kepemimpinan demokratik menjadi faktor pendorong kepada karyawan agar dapat bekerja dengan baik dan mencapai kinerja yang baik. Seorang pemimpin demokratik mendorong dan memberikan motivasi kepada bawahannya untuk meningkatkan kinerja karyawannya.

Berdasarkan pada latar belakang yang telah diuraikan sebelumnya maka rumusan masalah pertama dalam penelitian ini adalah: "Apakah gaya kepemimpinan demokratik berpengaruh positif dan signifikan terhadap kinerja karyawan di PT.Telkom Indonesia Palangka Raya" dan rumusan masalah kedua dalam penelitian ini adalah: "Apakah motivasi kerja berpengaruh secara positif dan signifikan dalam memoderasi gaya kepemimpinan demokratik terhadap kinerja karyawan di PT.Telkom Indonesia Palangka Raya?"

Tujuan dari penelitian ini adalah untuk mengetahui dan menguji apakah gaya kepemimpinan demokratik berpengaruh secara positif dan signifikan terhadap kinerja karyawan di PT.Telkom Indonesia Palangka Raya. Dan Untuk mengetahui dan menguji apakah motivasi kerja berpengaruh secara positif dan signifikan dalam memoderasi gaya kepemimpinan demokratik terhadap kinerja karyawan di PT.Telkom Indonesia Palangka Raya

Penelitian ini diharapkan dapat menambah wawasan, menjadi pengalaman bagi penulis, memperluas wawasan tentang teori manajemen sumber daya manusia. Dapat membantu mengembangkan pemikiran bagi PT.Telkom Indonesia Palangka Raya sebagai masukan dalam pertimbangan untuk pengambilan keputusan dan kebijaksanaan oleh pihak organisasi dalam memudahkan upaya perbaikan kinerja karyawan. Membantu menjadi bahan referensi bagi peneliti selanjutnya. Dan diharapkan penelitian ini dapat mengembangkan konsep sumber daya manusia yang berkaitan dengan gaya kepemimpinan demokratik, kinerja karyawan dan motivasi kerja.

\section{Metode Penelitian}

Penelitian ini berlokasi di kantor PT.Telkom Indonesia Palangka Raya, berdiri sejak tahun 1984. PT.Telkom Indonesia Palangka Raya terletak di Jl. Jenderal Ahmad Yani No.96, Pahandut, Kota Palangka Raya, Kalimantan Tengah. Dengan jumlah responden sebanyak 48 orang populasi dan sampel sebanyak 48 orang dengan menggunakan teknis sampling jenuh atau sensus.

Ruang lingkup penelitian ini adalah penelitian kuantitatif dengan menggunakan metode penelitian asosiatif. Dalam penelitian ini, metode asosiatif digunakan untuk mengetahui pengaruh gaya kepemimpinan demokratik terhadap kinerja karyawan dengan menggunakan motivasi sebagai variabel moderator. 


\section{Gaya Kepemimpinan Demokratis}

Definisi menurut Ariani (2015) yang mengacu pada penelitian Pasalong (2013) menjelaskan gaya kepemimpinan demokratik merupakan suatu cara yang dimiliki oleh seseorang dalam mempengaruhi sekelompok orang atau bawahan untuk bekerja sama. Gaya kepemimpinan demokratis dalam penelitian ini diukur melalui beberapa indikator: Keputusan dibuat bersama, menghargai potensi setiap bawahannya, mendengarkan kritik, saran, dan pendapat dari bawahan, dan melakukan kerjasama dengan bawahan.

\section{Kinerja}

Robbins (2010) kinerja adalah suatu hasil yang dicapai oleh karyawan dalam pekerjaannya menurut kriteria tertentu yang berlaku untuk suatu pekerjaan, dan kinerja yang dicapai oleh karyawan dapat diukur melalui persyaratan-persyaratan pekerjaan. Kinerja yang dicapai oleh karyawan dapat diukur melalui persyaratan-persyaratan pekerjaan dengan indikator: Kualitas, kuantitas, ketepatan waktu, efektivitas, kemandirian

\section{Motivasi}

Robbins dan Judge (2010) mendefinisikan motivasi (Motivation) sebagai proses yang menjelaskan intensitas, arah dan ketekunan seseorang individu untuk mencapai tujuannya. Motivasi kerja yang dimiliki oleh karyawan dapat diukur melalui indikator: Pekerjaan Itu Sendiri (The work itself), pencapaian (Achievement), pengakuan (Recognition), kondisi kerja (Working Condition), gaji dan upah (Wages and Salaries), hubungan antar pribadi (Interpersonal Relation), hubungan dengan atasan.

Teknik pengumpulan data yang dilakukan dalam penelitian ini adalah melalui kuesioner yaitu merupakan teknik pengumpulan data yang dilakukan dengan cara memberi seperangkat pertanyaan atau pernyataan tertulis kepada para responden untuk dijawab. Dan melalui analisis dokumen yaitu lebih mengarah pada bukti konkret. Dengan instrument ini akan dianalisa isi dari dokumen-dokumen yang dapat mendukung penelitian. Penelitian ini, teknik analisis data yang digunakan adalah Partial Least Square (PLS). Partial Least Square (PLS) merupakan analisis persamaan struktural (SEM) berbasis varian yang secara simultan dapat melakukan pengujian model pengukuran sekaligus pengujian model struktural.

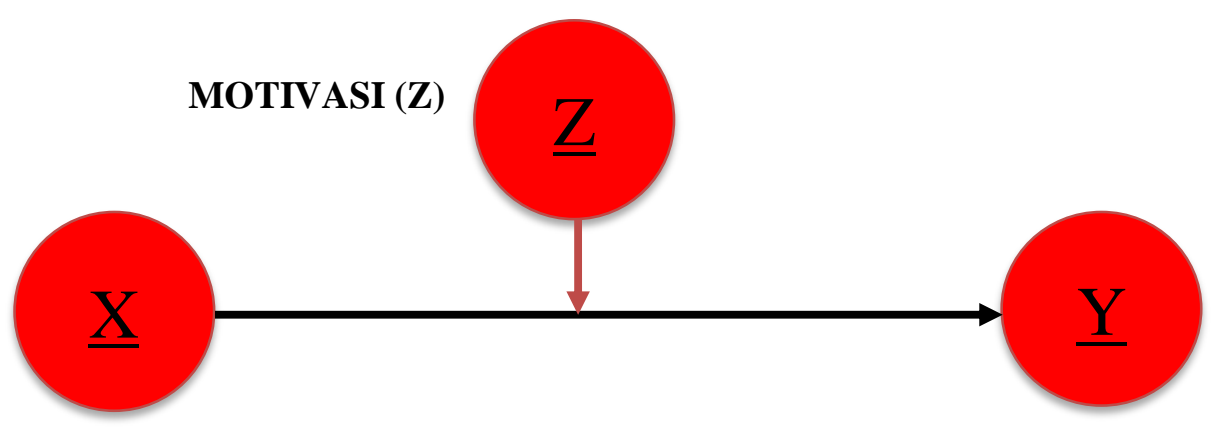




\section{Model Pengukuran Outer Model}

Outer model menurut Abdillah dan Hartono (2015) merupakan model pengukuran yang menggambarkan hubungan antara blok indikator dengan variabel latennya. Model pengukuran (outer model) digunakan untuk menguji validitas konstruk dan reliabilitas instrument.

Uji validitas dilakukan untuk mengetahui kemampuan instrument penelitian mengukur apa yang seharusnya diukur. Uji validitas yang digunakan dalam penelitian ini yaitu validitas konstruk. Validitas konstruk menunjukkan seberapa baik hasil yang diperoleh dari penggunaan suatu pengukuran sesuai teori-teori yang digunakan untuk mendefinisikan suatu konstruk (Hartono dalam Jogiyanto dan Abdillah, 2011:59)

\begin{tabular}{|c|c|c|}
\hline Uji Validitas & Parameter & Rule of Thumb \\
\hline \multirow[t]{3}{*}{$\begin{array}{l}\text { Validitas } \\
\text { Convergent }\end{array}$} & Loading Factor & $\begin{array}{l}\text { - }>0,70 \text { untuk confirmatory } \\
\text { research } \\
\text { - }>0,60 \text { untuk exploratory research }\end{array}$ \\
\hline & Communality & $\begin{array}{l}->0,50 \text { untuk confirmatory dan } \\
\text { exploratory research }\end{array}$ \\
\hline & $\begin{array}{l}\text { AVE (Average Variance } \\
\text { Extracted) }\end{array}$ & $\begin{array}{l}\text { - }>0,50 \text { untuk confirmatory dan } \\
\text { exploratory research }\end{array}$ \\
\hline \multirow{2}{*}{$\begin{array}{c}\text { Validitas } \\
\text { Discriminant }\end{array}$} & Cross Loading & - $>0,70$ untuk setiap variabel \\
\hline & $\begin{array}{l}\text { Akar kuadrat Ave dan } \\
\text { korelasi antar konstruk laten }\end{array}$ & $\begin{array}{l}\text { Akar kuadrat AVE > korelasi antar } \\
\text { konstruk laten }\end{array}$ \\
\hline
\end{tabular}

\section{Sumber : Abdillah dan Hartono, 2015}

\section{Uji Reliabilitas}

Reliabilitas menyatakan sejauh mana hasil atau pengukuran dapat dipercaya atau dapat diandalkan serta memberikan hasil pengukuran yang relative konsisten setelah dilakukan beberapa kali pengukuran. Reliabilitas menurut Abdillah dan Hartono (2015) menunjukkan tingkat konsistensi dan stabilitas alat ukur atau instrument penelitian dalam mengukur suatu konsep atau konstruk. Kemudian untuk pengujian reliabilitas pada model SEM sendiri menggunakan rumus Cronbach Alpha dan Composite Reliability. Uji reliabilitas dalam Partial Least Square (PLS) dapat menggunakan dua metode, yaitu Cronbach's Alpha dan nilai Composite Reliability. Cronbach's Alpha mengukur batas bawah nilai reliabilitas suatu konstruk sedangkan Composite Reliability mengukur nilai sesungguhnya reliabilitas suatu konstruk Jogiyanto (2011). Untuk dapat dikatakan suatu konstruk reliable, maka nilai Cronbach's Alpha harus > 0,60 dan nilai Composite Reliability harus > 0,70 (Jogiyanto, 2011).

\section{Model Struktural (Inner Model)}

Inner model merupakan model struktural untuk memprediksi hubungan kausalitas antar variabel laten. Inner model menurut Abdillah dan Hartono (2015) merupakan model struktural yang menggambarkan hubungan kausalitas antar variabel laten yang dibangun berdasarkan substansi teori. Model struktural dalam smartPLS dievaluasi 
dengan menggunakan $\mathrm{R}^{2}$ untuk konstruk dependen, nilai koefisien path atau t-value tiap path untuk uji signifikan antar konstruk dalam model struktural.

\section{Uji Model (GoF)}

Uji kecocokkan model adalah uji untuk memvalidasi model secara keseluruhan, menggunakan nilai Goodness Of Fit (GoF). GoF dikembangkan untuk mengevaluasi model pengukuran (outer model) dan model struktural (Inner Model), dan disamping itu menyediakan pengukuran sederhana untuk keseluruhan dari prediksi model. GoF merupakan ukuran tunggal yang digunakan untuk memvalidasi performa gabungan antara pengukuran dan model struktural, yang diperoleh dari akar nilai rata-rata Average Variance Extraced (AVE) dikalikan dengan akar nilai rata-rata R2 (R-Square). Nilai GoF antara 0-1 dengan interpretasi 0,1 (GoF kecil), 0,25 (GoF sedang), 0,36 (GoF besar) menurut (Uce Indahyanti, 2013).

\section{Pengujian Hipotesis}

Penelitian ini pengujian hipotesis adalah untuk mengetahui apakah variabel gaya kepemimpinan demokratik $(\mathrm{X})$ berpengaruh signifikan terhadap variabel kinerja karyawan (Y). Dan mengetahui apakah motivasi (Z) sebagai variabel moderator berpengaruh positif dan signifikan dalam memoderasi variabel gaya kepemimpinan demokratik $(\mathrm{X})$ terhadap variabel kinerja karyawan $(\mathrm{Y})$.

\section{Hasil dan Pembahasan}

Hasil Analisis dengan menggunakan validitas konvergen, sebagai berikut:

Tabel 1. validitas konvergen

\begin{tabular}{lcc}
\hline Variabel & Indikator & Outer Loadings \\
\hline Kepemimpinan Demokratik (X) & X1a & 0,839 \\
\cline { 2 - 3 } & X2b & 0,810 \\
\cline { 2 - 3 } & X3c & 0,913 \\
\cline { 2 - 3 } & X4d & 0,867 \\
\cline { 2 - 3 } & X5e & 0,798 \\
\cline { 2 - 3 } & X6f & 0,913 \\
\cline { 2 - 3 } & X7g & 0,886 \\
\hline Kinerja (Y) & X8h & 0,845 \\
\cline { 2 - 3 } & Y1a & 0,535 \\
\cline { 2 - 3 } & Y2b & 0,911 \\
\cline { 2 - 3 } & Y3c & 0,808 \\
\cline { 2 - 3 } & Y4d & 0,895 \\
\cline { 2 - 3 } & Y5e & 0,858 \\
\hline
\end{tabular}




\begin{tabular}{ccc}
\hline & Y6f & 0,660 \\
\cline { 2 - 3 } & Y7g & 0,826 \\
\cline { 2 - 3 } & Y8h & 0,541 \\
\cline { 2 - 3 } Motivasi (Z) & Y9i & 0,802 \\
\hline & Y10j & 0,716 \\
\hline & Z1a & 0,754 \\
\hline Z2b & 0,706 \\
\hline Z3c & 0,654 \\
\hline Z4d & 0,861 \\
\hline Z5e & 0,653 \\
\hline Z6f & 0,678 \\
\hline Z7g & 0,773 \\
\hline Z8h & 0,823 \\
\hline Z9i & 0,674 \\
\hline Z10j & 0,724 \\
\hline Z11k & 0,694 \\
\hline Z121 & 0,664 \\
\hline Z13m & 0,627 \\
\hline Z14n & 0,792 \\
\hline
\end{tabular}

Menurut Chin (1998) seperti yang dikutip oleh Jogiyanto (2011), nilai outer loadings antara $0,50-0,60$ sudah dianggap cukup untuk memenuhi syarat convergent validity. Data diatas menunjukkan bahwa semua indikator memiliki nilai outer loadings $\geq 0,50$ sehingga indikator dinyatakan layak atau valid untuk digunakan dalam penelitian dan dapat digunakan untuk analisis selanjutnya.

Tabel 2. Average Variant Extracted (AVE)

\begin{tabular}{lc}
\hline Variabel & AVE (Average Variant Extracted) \\
\hline Gaya Kepemimpinan Demokratik & 0,739 \\
\hline Kinerja & 0,587 \\
\hline Motivasi & 0,523 \\
\hline
\end{tabular}

Nilai AVE (Average Variant Extracted) gaya kepemimpinan demokratik, kinerja, dan motivasi $\geq 0,50$. Dengan demikian dapat dinyatakan bahwa indikator variabel penelitian layak atau valid.

\section{Uji Validitas Diskriminan}

Pengujian ini akan dilihat nilainya menggunakan cross loading. Suatu indikator dinyatakan memenuhi syarat discriminant validity apabila cross loadings indikator pada variabelnya adalah terbesar dibandingkan pada variabel lainnya. 
Tabel 3. discriminant validity

Masing-masing indikator pada variabel penelitian memiliki nilai cross loadings terbesar pada variabel yang dibentuknya dibandingkan dengan nilai cross loadings pada variabel lainnya. Berdasarkan hasil yang diperoleh tersebut, dapat dinyatakan bahwa indikator yang digunakan dalam penelitian ini telah memiliki discriminant validity yang

\begin{tabular}{|c|c|c|c|}
\hline Indikator Variabel & $\begin{array}{c}\text { Gaya Kepemimpim Demokratik } \\
(\mathrm{X})\end{array}$ & Kinerja (Y) & Motivasi (Z) \\
\hline $\mathrm{X} 1 \mathrm{a}$ & 0,839 & 0,636 & 0,516 \\
\hline $\mathrm{X} 2 \mathrm{~b}$ & 0,810 & 0,601 & 0,685 \\
\hline $\mathrm{X} 3 \mathrm{c}$ & 0,913 & 0,553 & 0,711 \\
\hline $\mathrm{X} 4 \mathrm{~d}$ & 0,867 & 0,605 & 0,816 \\
\hline $\mathrm{X} 5 \mathrm{e}$ & 0,798 & 0,751 & 0,670 \\
\hline X6f & 0,913 & 0,727 & 0,881 \\
\hline $\mathrm{X} 7 \mathrm{~g}$ & 0,886 & 0,494 & 0,693 \\
\hline $\mathrm{X} 8 \mathrm{~h}$ & 0,845 & 0,688 & 0,531 \\
\hline Y1a & 0,458 & 0,535 & 0,331 \\
\hline $\mathrm{Y} 2 \mathrm{~b}$ & 0,558 & 0,911 & 0,641 \\
\hline $\mathrm{Y} 3 \mathrm{c}$ & 0,685 & 0,808 & 0,569 \\
\hline Y4d & 0,773 & 0,895 & 0,702 \\
\hline Y5e & 0,688 & 0,858 & 0,619 \\
\hline Y6f & 0,482 & 0,660 & 0,441 \\
\hline Y7g & 0,651 & 0,826 & 0,634 \\
\hline Y8h & 0,246 & 0,541 & 0,436 \\
\hline Y9i & 0,597 & 0,802 & 0,494 \\
\hline Y10j & 0,373 & 0,716 & 0,482 \\
\hline Z1a & 0,512 & 0,384 & 0,754 \\
\hline $\mathrm{Z} 2 \mathrm{~b}$ & 0,268 & 0,441 & 0,706 \\
\hline $\mathrm{Z3c}$ & 0,367 & 0,369 & 0,654 \\
\hline $\mathrm{Z} 4 \mathrm{~d}$ & 0,855 & 0,647 & 0,861 \\
\hline $\mathrm{Z5e}$ & 0,460 & 0,290 & 0,653 \\
\hline Z6f & 0,578 & 0,408 & 0,678 \\
\hline $\mathrm{Z7g}$ & 0,740 & 0,759 & 0,773 \\
\hline $\mathrm{Z8h}$ & 0,744 & 0,714 & 0,823 \\
\hline Z9i & 0,550 & 0,484 & 0,674 \\
\hline $\mathrm{Z10j}$ & 0,626 & 0,545 & 0,724 \\
\hline Z11k & 0,494 & 0,507 & 0,694 \\
\hline Z121 & 0,532 & 0,374 & 0,664 \\
\hline $\mathrm{Z} 13 \mathrm{~m}$ & 0,331 & 0,290 & 0,627 \\
\hline Z14n & 0,689 & 0,548 & 0,792 \\
\hline
\end{tabular}

menyusun variabel masing-masing.

\section{Uji Reliabilitas}

Pengujian ini akan dilihat dari hasil nilai cronbach's alpha dan composite reliability. Suatu indikator dikatakan reliable atau memenuhi syarat cronbach's alpha dari masingmasing variabel penelitian harus $\geq 0,60$.

Tabel 4. Uji Reliabilitas

\begin{tabular}{lc}
\hline Variabel & Cronbach's Alpha \\
\hline Gaya Kepemimpinan Demokratik & 0,949 \\
\hline
\end{tabular}




\begin{tabular}{ll}
\hline Kinerja & 0,917 \\
\hline Motivasi & 0,930 \\
\hline
\end{tabular}

Nilai cronbach's alpha dari masing-masing variabel penelitian $\geq 0,60$. Dengan demikian hasil ini dapat menunjukkan bahwa masing-masing variabel penelitian telah memenuhi persyaratan nilai cronbach's alpha, sehingga dapat dinyatakan bahwa variabel memiliki tingkat reliabilitas yang baik, dan dapat diterima.

Tabel 4. Uji Reliabilitas

\begin{tabular}{lc}
\hline Variabel & Composite Reliability \\
\hline Gaya Kepemimpinan Demokratik & 0.958 \\
\hline Kinerja & 0,933 \\
\hline Motivasi & 0,938 \\
\hline
\end{tabular}

Nilai composite reliability variabel penelitian $\geq 0,70$. Hasil ini menunjukkan bahwa masing-masing variabel telah memenuhi composite reliability sehingga dapat dinyatakan bahwa variabel penelitian memiliki tingkat reliabilitas yang baik dan dapat diterima.

\section{Model Struktural Inner Model}

Pada penelitian ini akan dijelaskan hubungan antara variabel berdasarkan nilai yang didapat dari path coefficient.

Tabel 4. Hasil pengujian hipotesis

\begin{tabular}{|c|c|c|c|c|c|c|}
\hline Variabel & $\begin{array}{l}\text { Original } \\
\text { Sample } \\
(\mathrm{O})\end{array}$ & $\begin{array}{l}\text { Sample } \\
\text { Mean } \\
\text { (M) }\end{array}$ & $\begin{array}{l}\text { Standard } \\
\text { Deviation } \\
(\mathrm{STDEV})\end{array}$ & $\begin{array}{l}\text { T Statistics } \\
(|\mathrm{O} / \mathrm{STDEV}|)\end{array}$ & $\begin{array}{c}\mathrm{P} \\
\text { Values }\end{array}$ & Ket \\
\hline $\begin{array}{l}\text { Gaya } \\
\text { Kepemimpinan } \\
\text { Demokratik } \\
\text { Terhadap Kinerja }\end{array}$ & 0,452 & 0,452 & 0,165 & 2,749 & 0,003 & Diterima \\
\hline $\begin{array}{l}\text { Motivasi Terhadap } \\
\text { Kinerja }\end{array}$ & 0,346 & 0,356 & 0,157 & 2,208 & 0,014 & Diterima \\
\hline $\begin{array}{l}\text { Moderating Effect } \\
\text { Motivasi Terhadap } \\
\text { Kinerja }\end{array}$ & 0,086 & 0,084 & 0,045 & 1,934 & 0,027 & Diterima \\
\hline
\end{tabular}

Evaluasi path coefficient digunakan untuk menunjukkan seberapa kuat efek atau pengaruh variabel independen kepada variabel dependen, dan seberapa kuat variabel moderasi mempengaruhi hubungan antara variabel independen kepada variabel dependen. Nilai path coefficient terbesar ditunjukkan pada pengaruh gaya kepemimpinan demokratik terhadap kinerja sebesar 2,749. Kemudian, pengaruh terbesar kedua adalah pengaruh motivasi terhadap kinerja sebesar 2,208. Dan pengaruh yang paling kecil ditunjukkan oleh pengaruh motivasi sebagai moderating effect terhadap kinerja sebesar 1,934.

\section{Uji Model Goodness Of Fit (Gof)}


Nilai $R$-Square untuk variabel kinerja adalah 0,609. Perolehan nilai tersebut menjelaskan bahwa persentase besarnya kinerja sebesar $60,9 \%$. Penilaian goodness of fit diketahui dari nilai akar rata-rata Average Variance Extraced (AVE) dikalikan dengan akar nilai rata-rata $R$-Square. Adapun hasil perhitungannya adalah sebagai berikut:

$$
\begin{aligned}
& \text { GoF }=\sqrt{\overline{A V E} \times \overline{R^{2}}} \\
& \text { GoF }=\sqrt{0,616 \times 0,609} \\
& \text { GoF }=\sqrt{0,375144} \\
& \text { GoF }=0,612
\end{aligned}
$$

Menurut Indahyanti (2013) nilai GoF antara nilai 0-1 dengan persentase 0,36 (GoF besar). Maka hasil dari GoF pada penelitian ini masuk pada kategori GoF besar dan menunjukkan bahwa besarnya keragaman dari data penelitian ini dapat dijelaskan oleh model penelitian sebesar $61,2 \%$, sedangkan sisanya sebesar $38,8 \%$ dijelaskan oleh faktor lain yang berada diluar model penelitian ini. Dengan demikian, maka dapat dinyatakan bahwa model penelitian ini telah memiliki Gof (Goodness of Fit) yang baik.

\section{Uji Hipotesis}

Uji hipotesis pada penelitian ini dilakukan dengan melihat nilai, T Statistics dan nilai P-Values. Hipotesis penelitian dapat dinyatakan diterima apabila nilai PValues $\leq 0,05$. Taraf signifikansi 0,05 dan derajat kebebasan (df) dengan ketentuan yaitu $\mathrm{df}=\mathrm{n}-\mathrm{k}-1$

$\mathrm{df}=48-3-1$

df $=44$

Dari ketentuan tersebut diperoleh angka $t_{\text {tabel }}=1,680$. Maka dapat dilakukan pengambilan keputusan pada uji $\mathrm{T}$ statistics penelitian ini adalah sebagai berikut:

Hipotesis $1\left(\mathrm{H}_{1}\right) \quad: \mathrm{t}_{\text {hitung }} \geq \mathrm{t}_{\text {tabel }}$ maka Ho ditolak dan Ha diterima,

nilai $t_{\text {hitung }} 2,749 \geq t_{\text {tabel }} 1,680$ maka gaya kepemimpinan demokratik berpengaruh positif dan signifikan terhadap kinerja karyawan

Hipotesis $2\left(\mathrm{H}_{2}\right) \quad: t_{\text {hitung }} \geq t_{\text {tabel }}$ maka Ho ditolak dan Ha diterima, nilai $t_{\text {hitung }} 1,934 \geq t_{\text {tabel }} 1,680$ maka motivasi kerja berpengaruh positif dan signifikan dalam memoderasi gaya kepemimpinan demokratik terhadap kinerja karyawan

Skor koefisien inner model menunjukkan tingkat signifikansi dalam pengujian hipotesis. Skor koefisien inner model yang ditunjukkan oleh T statistics harus di atas 1,96 untuk hipotesis dua ekor (two tailed) dan di atas 1,64 untuk hipotesis satu ekor (one-tailed) untuk pengujian hipotesis pada alpha 5\% dan tingkat keyakinan 95\% (Jogiyanto, 2011). Maka hasilnya adalah dengan menggunakan pengujian hipotesis satu ekor (one-tailed) hasilnya 2,749 $\geq 1,64$ maka dinyatakan bahwa gaya kepemimpinan demokratik berpengaruh positif dan signifikan terhadap kinerja karyawan, dan 1,934 $\geq$ 1,64 maka dinyatakan bahwa motivasi kerja berpengaruh positif dan signifikan dalam memoderasi gaya kepemimpinan demokratik terhadap kinerja karyawan

Selanjutnya dari data tersebut maka dapat dilakukan pengambilan keputusan pada uji hipotesis penelitian ini sebagai berikut:

Hipotesis $1\left(\mathrm{H}_{1}\right) \quad$ : P-Values $\leq 0,05$ maka Ho ditolak Ha diterima, 
Hipotesis $2\left(\mathrm{H}_{2}\right)$

$0,003 \leq 0,05$ maka gaya kepemimpinan demokratik berpengaruh positif dan signifikan terhadap kinerja karyawan, dengan adanya gaya kepemimpinan demokratik yang digunakan maka akan meningkatkan kinerja karyawan : $\mathrm{P}$-Values $\leq 0,05$ maka Ho ditolak Ha diterima, $0,027 \leq 0,05$ maka motivasi kerja berpengaruh positif dan signifikan dalam memoderasi gaya kepemimpinan demokratik terhadap kinerja karyawan, serta motivasi kerja memperkuat pengaruh gaya kepemimpinan demokratik terhadap kinerja karyawan

\section{Pengaruh Gaya Kepemimpinan Terhadap Kinerja Karyawan}

Berdasarkan hasil pengujian hipotesis pertama, dapat disimpulkan bahwa variabel gaya kepemimpinan demokratik berpengaruh positif dan signifikan terhadap kinerja karyawan. Hal ini sesuai dengan hipotesis yang menyatakan bahwa gaya kepemimpinan demokratik berpengaruh terhadap kinerja karyawan yang dikembangkan dari hasil penelitian. Pengaruh yang didapat dari hasil penelitian ini adalah sebesar 2,749 dilihat dari $\mathrm{T}$ statistics dan dinyatakan ada pengaruh gaya kepemimpinan demokratik terhadap kinerja karyawan dan nilai $\mathrm{P}$ Values sebesar 0,003 dinyatakan ada pengaruh secara positif dan signifikan pada tingkat signifikan 0,05 .

Hal ini sesuai dengan teori menurut Hadari Nawawi (2016) menjelaskan bahwa gaya kepemimpinan yang dimiliki oleh seorang pemimpin harus dapat mengidentifikasi, mengukur, menilai, mendorong, memperbaiki, dan memberi penghargaan serta sanksi pada karyawan sesuai dengan kinerja masing-masing karyawan.

Penelitian ini menyatakan bahwa gaya kepemimpinan demokratik pada PT.Telkom Indonesia Palangka Raya dapat memberikan pengaruh secara positif dan signifikan terhadap kinerja karyawan, atau dengan kata lain pemimpin PT.Telkom Indonesia Palangka Raya memberikan pengaruh yang positif dan pengaruh yang langsung kepada karyawan sehingga dapat meningkatkan kinerja karyawan. Peran pemimpin sangat baik karena dapat mendorong semangat kerja karyawannya, sehingga menghasilkan performa kinerja yang baik.

\section{Pengaruh Motivasi Sebagai Variabel Moderator Kepada Gaya Kepemimpinan Demokratik Terhadap Kinerja Karyawan}

Berdasarkan hasil pengujian pada hipotesis kedua menunjukkan bahwa motivasi sebagai variabel moderator berpengaruh secara positif dan signifikan terhadap kinerja karyawan. Hal ini sesuai dengan hipotesis yang menyatakan bahwa motivasi sebagai moderator berpengaruh terhadap kinerja karyawan yang dikembangkan dari hasil penelitian. Pengaruh yang didapat dari hasil penelitian ini adalah sebesar 1,934 dilihat dari $\mathrm{T}$ statistics dan dinyatakan motivasi kerja berpengaruh memoderasi gaya kepemimpinan demokratik terhadap kinerja karyawan dan nilai P Values sebesar 0,027 dinyatakan ada pengaruh secara positif dan signifikan pada tingkat signifikan 0,05.

Hal ini sesuai dengan teori Menurut Gomez (2013) bahwa kinerja adalah fungsi dari motivasi dan kemampuan karyawan. Kemampuan melekat dalam diri seseorang dan merupakan bawaan sejak lahir serta diwujudkan dalam tindakannya dalam bekerja, sedangkan motivasi sebagai aspek yang sangat penting untuk menggerakkan kreativitas dan kemampuan seseorang dalam melakukan suatu pekerjaan, serta selalu bersemangat 
dalam menjalankan pekerjaan tersebut.

Penelitian ini menyatakan bahwa motivasi sebagai variabel moderator pada PT.Telkom Indonesia Palangka Raya dapat memberikan pengaruh secara positif, artinya bahwa motivasi memperkuat pengaruh antara gaya kepemimpinan demokratik terhadap kinerja karyawan. Dengan kata lain bahwa motivasi yang diberikan oleh pemimpin PT.Telkom Indonesia Palangka Raya memperkuat pengaruh gaya kepemimpinan demokratik yang diterapkan terhadap kinerja karyawan. Dan motivasi sebagai variabel moderator pada PT.Telkom Indonesia Palangka Raya memberikan pengaruh yang signifikan, artinya bahwa motivasi memberikan pengaruh atau dampak yang berarti kepada gaya kepemimpinan demokratik yang diterapkan oleh pemimpin terhadap kinerja karyawan.

Motivasi sebagai variabel moderator pada hubungannya dengan pengaruh gaya kepemimpinan demokratik terhadap kinerja karyawan, membuktikan secara nyata bahwa seorang pemimpin harus memberikan motivasi kepada bawahannya agar dapat meningkatkan performa kerja karyawan sehingga menghasilkan kinerja karyawan yang maksimal bagi organisasi.

\section{SIMPULAN}

Setelah peneliti melakukan analisis mengenai pengaruh gaya kepemimpinan demokratik terhadap kinerja karyawan dengan menggunakan motivasi sebagai variabel moderator pada PT.Telkom Indonesia Palangka Raya, maka penulis menyimpulkan bahwa: Gaya kepemimpinan demokratik (X) berpengaruh positif dan signifikan terhadap kinerja karyawan (Y) pada PT.Telkom Indonesia Palangka Raya. Dan Motivasi $(Z)$ berpengaruh positif dan signifikan dalam memoderasi gaya kepemimpinan demokratik (X) terhadap kinerja karyawan (Y) dan memperkuat pengaruh gaya kepemimpinan demokratik terhadap kinerja karyawan pada PT.Telkom Indonesia Palangka Raya .

Hasil penelitian yang telah dilakukan, maka peneliti memberikan saran sebagai berikut: Bagi pemimpin PT.Telkom Indonesia Palangka Raya disarankan agar dapat meningkatkan kerja sama dengan karyawan terkait dengan membuat keputusan bersama dengan karyawan, dapat mendorong karyawan untuk dapat hadir tepat waktu pada saat bekerja agar dapat meningkatkan efisien waktu untuk bekerja, memberikan dukungan motivasi yang lebih lagi kepada karyawan agar karyawan memiliki motivasi kerja yang meningkat sehingga menghasilkan kinerja yang maksimal. Bagi peneliti selanjutnya yang tertarik untuk meneliti variabel penelitian ini diharapkan dapat menggali lebih jauh permasalahan yang berhubungan dengan gaya kepemimpinan demokratik, kinerja karyawan dan motivasi kerja sehingga penelitian menjadi lebih lengkap, diharapkan dapat mengkaji lebih mendalam pada cakupan yang lebih luas atau pada instansi atau perusahaan lain, sehingga peneliti selanjutnya diharapkan dapat memberi kontribusi yang lebih berarti terutama dalam pemahaman tentang hal yang mempengaruhi kinerja karyawan

\section{Referensi}


Abdillah Willy, \& Jogiyanto. (2015). Partial Least Square (PLS) Structural Equation Modeling (SEM) Dalam Penelitian Bisnis. Yogyakarta: Penerbit Andi

Ardana Komang, \& Ni Wayan Mujiati, I Wayan Mudiartha. (2012). Manajemen Sumber Daya Manusia. Yogyakarta: Graha Ilmu

Athoillah Anton. (2010). Dasar-Dasar Manajemen. Bandung: Pustaka Setia.

Badrudin. (2014). Dasar-dasar Manajemen. Bandung: Alfabeta

Dadang Kahmad, \& Khaerul Umam. (2012). Manajemen Organisasi. Bandung: Pustaka Setia

Dimyati Hamdan, \& Endang Soetari. (2014). Model Kepemimpinan dan Sistem Pengambilan Keputusan. Bandung: Pustaka Setia

Fahmi Irham. (2014). Manajemen Kepemimpinan Teori dan Aplikasi. Bandung: Alfabeta

Ghozali Imam, \& Hengky Latan. (2015). Partial Least Squares Konsep Teknik dan Aplikasi Menggunakan Program SmartPLS 3.0. Semarang: Universitas Diponegoro Semarang

Hutagalung Christofel. (2016). Efek Moderator Gaya Kepemimpinan Pada Pengaruh Motivasi Terhadap Kinerja Karyawan. Yogyakarta: Melalui https://repository.usd.ac.id/7315/2/122214066_full.pdf

Indriantoro, Bambang. (2013). Metodologi Penelitian Bisnis. Yogyakarta: BPFE

Mangkuprawira, Sjafri. (2014). Manajemen Sumber Daya Manusia Strategik. Bogor: GT

Muryanto Eko. (2011). Pengaruh Kompensasi Terhadap Kinerja Dengan Motivasi Kerja Sebagai Variabel Moderating. Yogyakarta: Melalui https://core.ac.uk/download/pdf/16508359.pdf

Prabu A. M. (2010). Evaluasi Kinerja SDM. Bandung: Refika Aditama

Prabu A. M. (2010). Manajemen Sumber Daya Manusia Perusahaan. Bandung: Rosda

Sarwono Jonathan, \& Umi Narimawati. (2015). Membuat Skripsi Tesis dan Disertasi Partial Least Square SEM. Yogyakarta: Penerbit Andi

Sekaran Uma, \& Roger Bougie. (2017). Metode Penelitian Untuk Bisnis Edisi satu. Jakarta: Salemba Empat

Sekaran Uma, \& Roger Bougie. (2017). Metode Penelitian Untuk Bisnis Edisi dua. Jakarta: Salemba Empat

Siagian Sondang. (2015). Teori dan Praktek Kepemimpinan. Jakarta: Rineka Cipta Siagian Sondang. (2014). Teori Motivasi dan Aplikasinya. Jakarta: Rineka Cipta Siswanti Yuni. (2018). Pengaruh Kepemimpinan Terhadap Kinerja Karyawan Dengan Motivasi Sebagai Variabel Moderator Pada Bank Lampung. Lampung: Melalui http://digilib.unila.ac.id/37246/3/3.\%20TESIS\%20FULL\%20TANPA\%20BAB

\%20PEMBAHASAN.pdfTahir Arifin. 2014. PerilakuOrganisasi. Yogyakarta : Deepublish

Sudaryono. (2017). Pengantar Manajemen Teori dan Kasus. Yogyakarta: CAPS

Sugiyono. (2013). Metode Penelitian Manajemen. Yogyakarta: Alfabeta

Suwatno, D. J. P. (2014). Manajemen SDM Dalam Organisasi Publik dan Bisnis. Bandung: Alfabeta

Tahir Arifin. (2014). Perilaku Organisasi. Yogyakarta: Deepublish

Thoha Miftah. (2015). Kepemimpinan Dalam Manajemen. Jakarta: RajaGrafindo Persada

Thoha Miftah. (2014). Perilaku Organisasi Konsep Dasar dan Aplikasinya. Jakarta: 
Grafindo Persada

Veithzal Rivai, Bachtiar, \& Boy Rafli Amar. (2012). Pemimpin dan Kepemimpinan

Dalam Organisasi. Jakarta: Rajawali Pers

Wiratna Sujarweni. (2015). Metodologi Penelitian Bisnis dan Ekonomi. Yogyakarta:

Pustaka Baru Press

Wibowo. (2014). Manajemen Kinerja. Jakarta : PT Raja Grafindo Persada

Yukl Gary. (2005). Kepemimpinan Dalam Organisasi Edisi ke-5. Jakarta: Indeks 